\title{
Health Care Utilization and Expenditures of Patients with Diabetes Comorbid with Depression Disorder: A National Population-Based Cohort Study
}

\author{
Chun-Jen Huang ${ }^{1,2}$, Hui-Min Hsieh ${ }^{3}$, Herng-Chia Chiư, Peng-Wei Wang ${ }^{1,2}$, \\ Mei-Hsuan Lee ${ }^{5}$, Chih-Yi Li ${ }^{6}$, and Ching-Hua Lin ${ }^{2,7} \bowtie$ \\ ${ }^{1}$ Department of Psychiatry, Kaohsiung Medical University Hospital, Kaohsiung,Taiwan \\ ${ }^{2}$ Department of Psychiatry, Faculty of Medicine, College of Medicine, Kaohsiung Medical University, Kaohsiung, Taiwan \\ ${ }^{3}$ Department of Public Health, Kaohsiung Medical University, Kaohsiung,Taiwan \\ ${ }^{4}$ Department of Healthcare Administration and Medical Informatics, College of Health Science, Kaohsiung Medical University, Kaohsiung, Taiwan \\ ${ }^{5}$ Division of Pulmonary and Critical Care Medicine, Department of Internal Medicine, Kaohsiung Medical University, Kaohsiung, Taiwan \\ ${ }^{6}$ Division of Secretary, Kaohsiung Medical University Hospital, Kaohsiung Medical, Kaohsiung, Taiwan \\ ${ }^{7}$ Kaohsiung Municipal Kai-Syuan Psychiatric Hospital, Kaohsiung, Taiwan
}

Objective The study investigated to compare health care utilization and expenditures between diabetic patients with and without depression in Taiwan.

Methods Health care utilization and expenditure among diabetic patients with and without depression disorder during 2000 and 2004 were examined using Taiwan's population-based National Health Insurance claims database. Health care utilization included outpatient visits and the use of inpatient services, and health expenditures were outpatient, inpatient, and total medical expenditures. Moreover, general estimation equation models were used for analyzing the factors associated with outpatient visits and expenditures. Multiple logistic regression analysis was applied for identifying the factors associated with hospitalization.

Results The average annual outpatient visits and annual total medical expenditures in the study period were 44.23-52.20; NT\$87,496133,077 and 30.75-32.92; NT\$64,411-80,955 for diabetic patients with and without depression. After adjustment for covariates, our results revealed that gender and complication were associated with out-patient visits. Moreover, the time factor was associated with the total medical expenditure, and residential urbanization and complication factors were associated with hospitalization.

Conclusion Health care utilization and expenditures for diabetic patients with depression were significantly higher than those without depression. Sex, complications, time, and urbanization are the factors associated with health care utilization and expenditures.

Psychiatry Investig 2017;14(6):770-778

Key Words Health care utilization, Expenditure, Depression, Diabetes.

\section{INTRODUCTION}

Diabetes mellitus, a chronic and disabling disease, majorly contributes to disability-adjusted life years. ${ }^{1,2}$ Similarly, major depressive disorder (MDD) is a leading cause of disability among

Received: August 6, 2016 Revised: January 14, 2017

Accepted: March 31, 2017 Available online: August 29, 2017

$\triangle$ Correspondence: Ching-Hua Lin, MD, PhD

Kaohsiung Municipal Kai-Syuan Psychiatric Hospital, 130 Kai-Syuan 2nd Rd., Ling-Ya District, Kaohsiung 802, Taiwan

Tel: +886-7-751-3171, Fax: +886-7-16-1843, E-mail: chua.lin@msa.hinet.net

(a) This is an Open Access article distributed under the terms of the Creative Commons Attribution Non-Commercial License (http://creativecommons.org/licenses/bync/4.0) which permits unrestricted non-commercial use, distribution, and reproduction in any medium, provided the original work is properly cited. chronic medical conditions. ${ }^{3,4}$ The World Health Organization categorizes depression as one of the most disabling clinical diagnosis estimated to affect approximately 340 million people worldwide. ${ }^{5}$ Depression disorder affects the productivity of workers through high absenteeism and reduced on-the-job output and can lead to disability. ${ }^{6}$ Diabetes mellitus (DM) is an epidemic disease in the world. Marked changes in human health behaviors and lifestyle have resulted in higher incidence and prevalence of DM. ${ }^{7}$ It has been recently estimated that the global prevalence of diabetes is $8.3 \%{ }^{8} \mathrm{DM}$ is a prevalent disease that causes significant morbidity and mortality and is associated with substantial care utilization and expenditure ${ }^{9,10} \mathrm{DM}$ and its complications impose a heavy burden on personal and 
public health globally. The number of persons with diabetes is also rising because of population growth, aging, urbanization, and increasing prevalence of obesity and physical inactivity. The potential for increase in persons with diabetes is greatest in Asia. ${ }^{8,11}$ Type $2 \mathrm{DM}$ has become an important public health threat for the ethnic Chinese population living in mainland China, Hong Kong, Taiwan, and Singapore, with a prevalence of one-fifth of the adult population. ${ }^{8,9}$ Given the genetic susceptibility and rapid westernization of food and lifestyle, a striking increase in incidence and prevalence of type $2 \mathrm{DM}$ is anticipated. $^{8,12}$

Comorbid mental and physical illness, often categorized as "chronic illness with complexity (CIC)," is a new and emerging research area. CIC is defined as multiple chronic conditions occurring simultaneously regardless of the causal pathways and associations. ${ }^{13,14}$ Mental illnesses comorbid with physical illnesses are often considered discordant ${ }^{15,16}$ because of the challenges involved with self-management and the varying treatment regimens for both types of illnesses. For example, the prognosis of diabetes largely depends on the efficiency of routine self-management. Similar to other chronic diseases, comorbid mental illnesses can substantially affect diabetes management. ${ }^{17}$ Depressive symptoms, depression and anxiety disorders, and diabetes-specific distress are common in patients with diabetes. All factors are associated with several bio behavioral variables, including poor disease management, high health care costs, and mortality. ${ }^{17,18}$

Many studies have discussed the health care utilization and expenditures of patients with diabetes comorbid with physical complications. ${ }^{19-22}$ However, few studies have focused on mental illnesses in patients with diabetes, although these patients are more predisposed to anxiety and depression than the general population. ${ }^{23-26}$ Most studies on the association between depression and diabetes have been conducted in Western countries. ${ }^{17,27-31}$ Very few evidence is present on the aforementioned association in Asian countries, particularly in China, although analyses from other cultures are a critical component of epidemiology. Cultural factors and explanatory disease models may differ in patients from Asian and Western countries, which affects the ability of patients to report the symptoms of mental illnesses and disease presentation. As stated by Lloyd et al. $^{32}$ in a review article, cultural diversity must be considered while assessing patients with mental illnesses. ${ }^{1}$ According to our review of relevant literature, thus far, few studies have elaborated on the time factor associated with health care utilization and expenditures in patients with diabetes. Hence, the present study investigated health care utilization and expenditures of patients with diabetes comorbid with depression in a clinical setting and identified the associated factors.

\section{METHODS}

\section{National health insurance program and data source}

Taiwan's National Health Insurance (NHI) program is a mandatory, single-payer system established in 1995 under the NHI Administration (NHIA); approximately $98 \%$ of all Taiwanese residents are enrolled in the program, and almost all medical care providers in Taiwan, including those employed at medical and primary care centers, are contracted by the NHIA to provide outpatient and inpatient services. Through a fee-forservice payment system, all health care providers fill monthly service claims to the NHI to get reimbursement for their medical fees. These claims include inpatient, ambulatory, and home care, and information such as patient demographics (age and sex), clinical details [disease and procedure codes based on the International Classification of Diseases, Ninth Revision, Clinical Modification (ICD-9-CM)], and health care utilization and expenditure (hospital days, drug use, and costs).

Our study was conducted retrospectively using a study cohort drawing from a random sample in the National Health Research Institutes (NHRI) database from 2000 to 2004. The cohort was randomly selected from the population that enrolled in the NHI in 2000 ( $n=23,735,407)$. Excluding those from the uninsured population, a sample group of 200,432 patients represented $1 \%$ of the total NHI database. No significant differences were observed in age, sex, or the average insured payrollrelated amount between the random sample and whole population. Although the administrative claims database has limitations regarding the accuracy of diagnostic coding, ${ }^{33,34}$ the database has been validated and research based on the database has been previously published. ${ }^{23-25,35-37}$

\section{Definitions of diabetes and depression disorder}

Patients with at least two service claims for diabetes (ICD9-CM 250) for ambulatory care or with one service claim for inpatient care between 2000 and 2004 were defined as having diabetes. $^{23-25,35,38}$ To reduce possible coding and diagnostic errors, these patients were classified into type 1 diabetes according to ICD-9-CM 250.x1 and 250.x3 and type 2 diabetes according to ICD-9-CM 250.x0 and 250.x2. Patients with at least one service claim between 2000 and 2004 for either ambulatory or inpatient care with a principal diagnosis of depression (ICD-9-CM 296.2x, 296.3x, 296.82, 300.4, 309.0, 309.1, and 311 ) were defined as having depression. ${ }^{23}$ Total 5,636 patients with diabetes were identified, including 144 (2.55\%) patients with depression.

\section{Health care utilization and expenditures}

Health care utilization included outpatient visits and hospital admission per person per year. Outpatients included those 
who visited physician clinics and hospital outpatient departments. Hospital admission was defined as admission to a general or psychiatric hospital.

Healthcare expenditure included outpatient, inpatient, and total medical expenditures per person per year. Outpatient expenditure included payments for office-based provider visits and hospital outpatient visits. Outpatient health expenditures consisted of physician fee, medication, laboratory exams, and others. Inpatient expenditures included 14 items, including medication, room, procedure, imaging, and others. ${ }^{35,39}$ To reflect the real monetary value, the mean expenditures were adjusted using the consumer price index for the Taiwanese currency in 2004.

\section{Age, income, time, and other covariates}

Patient demographics characteristics included age, sex, urbanization, and income, whereas disease characteristics included types of complications and diabetes. Patient ages were calculated as the year difference of mid-year (June 30) and patient birthdays. Age was categorized as $<45,45-64$, and $\geq 65$ years, and urbanization was categorized as urban, suburban, and rural. ${ }^{23-25,35,36}$ Income status has been considered a critical risk factor for depression, anxiety symptoms, and diabetes ${ }^{40,41}$ andit has also been associated with higher health care utilization and medical expenditures under the NHI program. Therefore, we included income status variables for investigating the association between income levels and health utilization and expenditures. Income level was classified into dependent, $<$ US\$666 (NT\$20,000), US\$666-1332 (NT\$20,000-39,999), and $\geq$ US $\$ 1333$ ( $\geq N T \$ 40,000)$. In addition, we included individual complications (neurological, peripheral vascular, cardiovascular, renal, endocrinal/metabolic, ophthalmic, and others) based on ICD9-CM diagnosis codes for specifically characterizing patients with diabetes comorbid with and without depression. Detailed ICD-9 diagnosis codes were listed in the Supplementary Table 1 (in the online-only Data Supplement). Finally, we included dummy time variables for each year from 2000 to 2004.

\section{Statistical analyses}

Student's $t$ test was used for comparing the differences of health care utilization and expenditures between patients with diabetes comorbid with and without depression each year. After adjustment for time, we primarily identified the NHI 2000 cohort and followed the patients with depression for determining the factors possibly associated with health care utilization and expenditures. General estimation equations (GEE) were used for examining the factors associated with outpatient visits and the total medical expenditure of patients with diabetes comorbid with depression after adjusting for covariates.
Multiple logistic regression analysis was used for exploring the associations between the factors of interest and hospitalization of patients with diabetes comorbid with depression. All analyses were performed using SPSS version 12.0 (SPSS Inc., Chicago, IL, USA).

\section{RESULTS}

The demographic data of patients with diabetes comorbid with and without depression disorder are shown in Table 1. Health care utilization and expenditures were compared among the two aforementioned cohorts throughout the study period (2000-2004) (Table 2). The average numbers of annual outpatient visits of patients with diabetes comorbid with depression was 44.23 (SD, \pm 22.96$)$ in 2000 and 52.20 ( \pm 32.24$)$ in 2004 and for those without depression were $31.08( \pm 20.71)$ in 2000 and $32.92( \pm 22.74)$ in 2004 . The annual average of hospital admissions for patients with diabetes comorbid with and without depression ranged from 0.93 (SD, \pm 1.46$)$ to $1.02( \pm 1.87)$ and from $0.49( \pm 1.16)$ to $0.53( \pm 1.26)$, respectively.

The average annual outpatient, inpatient, and total expenditures increased for the two cohorts across the five-year period. The outpatient visits, hospital admission, outpatient expenditures, inpatient expenditures, and total expenditures were significantly higher for patients with diabetes comorbid with depression than for those without depression.

The associations between longitudinal outpatient visits and associated factors analyzed using the GEE model are presented in Table 3. Sex and complications were significant factors in outpatient visits of patients with diabetes comorbid with depression. After adjusting for other covariates, men had 6.27 times less outpatient visits [95\% confidence interval (CI): -12.12$-0.42]$ than did women. Compared with patients without complications, those with ophthalmic complications had 6.04 times more outpatient visits (95\% CI: 0.04-12.03).

The factors associated with the total medical expenditures for patients with diabetes comorbid with depression were analyzed using the GEE model (Table 3). Time significantly affected the total medical expenditures of patients with diabetes comorbid with depression. After adjustment for other factors, the total medical expenditures in 2004 were NT\$25,837 (95\% CI: 7,192-44,483), which is more than that reported in 2000.

The risk of hospitalization in the observation period was analyzed using logistic regression models (Table 4). Urbanization and complications were the significant factors in the hospitalization of patients with diabetes comorbid with depression. After adjustment for other factors, patients living in rural areas had 2.859 times more incidences of hospitalization (95\% CI: 1.051-7.777) than their urban counterparts. Compared with patients without complications, those with ophthalmic 
Table 1. Demographic data of the diabetic patients with depression disorder and without depression disorder

\begin{tabular}{|c|c|c|}
\hline \multirow[t]{2}{*}{ Variables } & $\begin{array}{c}\text { Diabetic patients with depression } \\
\text { disorder }(\mathrm{N}=144)\end{array}$ & $\begin{array}{c}\text { Diabetic patients without depression } \\
\text { disorder }(\mathrm{N}=5,492)\end{array}$ \\
\hline & $\mathrm{N}(\%)$ & $\mathrm{N}(\%)$ \\
\hline \multicolumn{3}{|l|}{ Gender } \\
\hline Female & $59(59.0)$ & $2,861(52.10)$ \\
\hline Male & $85(41.0)$ & $2,631(47.90)$ \\
\hline \multicolumn{3}{|l|}{ Age } \\
\hline$<45$ years & $12(8.3)$ & $596(10.90)$ \\
\hline $45-64$ & $67(46.5)$ & $2,506(45.60)$ \\
\hline$\geq 65$ & $65(45.1)$ & $2,390(43.50)$ \\
\hline \multicolumn{3}{|l|}{ Urbanization } \\
\hline Urban & $92(63.9)$ & $3,426(62.40)$ \\
\hline Suburban & $4(2.8)$ & $256(4.70)$ \\
\hline Rural & $48(33.3)$ & $1,810(33.00)$ \\
\hline \multicolumn{3}{|l|}{ Income } \\
\hline$\geq \mathrm{NT} \$ 40,000(\geq \mathrm{US} \$ 1,333)$ & $5(3.5)$ & $340(6.20)$ \\
\hline NT\$20,000-39,999 (US\$666-1,332) & $11(7.6)$ & $549(10.00)$ \\
\hline$<\mathrm{NT} \$ 20,000(\mathrm{US} \$ 666)$ & $86(59.7)$ & $2,699(49.10)$ \\
\hline Dependents & $42(29.2)$ & $1,904(34.70)$ \\
\hline \multicolumn{3}{|l|}{ Complication } \\
\hline Neurological & $53(36.8)$ & $4,160(75.70)$ \\
\hline Peripheral vascular & $19(13.2)$ & $1,332(24.30)$ \\
\hline Cardiovascular & $103(71.5)$ & $5,030(91.60)$ \\
\hline Renal & $26(18.1)$ & $462(8.40)$ \\
\hline Endocrine/metabolic & $53(36.8)$ & $1,938(35.30)$ \\
\hline Ophthalmic & $52(36.1)$ & $3,554(64.70)$ \\
\hline Others & $50(34.7)$ & $4,440(80.80)$ \\
\hline \multicolumn{3}{|l|}{ Diabetes } \\
\hline Type 1 & $5(3.5)$ & $185(3.40)$ \\
\hline Type 2 & $121(84.0)$ & $4,653(84.70)$ \\
\hline
\end{tabular}

Dependents: including family dependents, students and the unemployed. Exchange rate between US\$:NT\$=1:30

complications had about 3 times more incidence of hospitalization (95\% CI: 1.167-7.720).

\section{DISCUSSION}

This study has several key findings. First, compared with diabetic patients without depression, those with depression availed more health care services and had higher expenditures during the study period. These results were consistent with those of previous studies. ${ }^{17,27-31}$ The number of persons with diabetes is also rising because of population growth, aging, urbanization, and increasing prevalence of obesity and physical inactivity. The potential for increase in persons with diabetes is greatest in Asia. ${ }^{8,11}$ Type $2 \mathrm{DM}$ has become an important public health threat for the ethnic Chinese population living in mainland China, Hong Kong, Taiwan, and Singapore, with a prevalence of one-fifth of the adult population. ${ }^{8,42}$ Given the genetic susceptibility and rapid westernization of food and lifestyle, a striking increase in incidence and prevalence of type $2 \mathrm{DM}$ is anticipated. ${ }^{8,12}$ Most previous studies were conducted on patients from Western countries and not on those from ethnic Chinese societies. Some differences, including those related with genetic factors, obesity, diet, culture, lifestyle, and medical source, exist between ethnic Chinese societies and Western countries.

Second, the study findings indicated that men used less health care services than women do. The finding is consistent with that of a previous study that reported women as being more capable of identifying depressive symptoms and more willing to seek help. ${ }^{43}$ In a study in China, the male sex was as- 
Table 2. Healthcare utilization and expenditure between diabetic patients with depression disorder and without depression disorder and mental illnesses per person per year

\begin{tabular}{|c|c|c|}
\hline \multirow{2}{*}{ Variables } & Diabetic patients with depression disorder & Diabetic patients without depression disorder \\
\hline & Mean (SD) & Mean $(\mathrm{SD})$ \\
\hline \multicolumn{3}{|l|}{2000} \\
\hline \multicolumn{3}{|l|}{ Health utilization } \\
\hline Outpatient visits & $44.23(22.96)$ & $31.08(20.71)^{* * *}$ \\
\hline Hospital admission & $1.02(1.87)$ & $0.52(1.15)^{* * *}$ \\
\hline \multicolumn{3}{|l|}{ Health expenditure } \\
\hline Outpatient expenditure & $50,693(50,194)$ & NT $\$ 37,029(61,788)^{* *}$ \\
\hline Inpatient expenditure & $36,803(86,103)$ & NT $\$ 24,187(113,569)$ \\
\hline Total expenditure & $87,496(103,703)$ & NT $\$ 64,411(130,063)^{*}$ \\
\hline \multicolumn{3}{|l|}{2001} \\
\hline \multicolumn{3}{|l|}{ Health utilization } \\
\hline Outpatient visits & $45.46(23.83)$ & $30.85(20.38)^{* * *}$ \\
\hline Hospital admission & $0.99(1.66)$ & $0.52(1.22)^{* * *}$ \\
\hline \multicolumn{3}{|l|}{ Health expenditure } \\
\hline Outpatient expenditure & $53,217(60,119)$ & NT $\$ 38,283(65,256)^{* *}$ \\
\hline Inpatient expenditure & $41,960(111,427)$ & NT \$29,747 $(123,223)$ \\
\hline Total expenditure & $95,177(133,739)$ & NT $\$ 68,030(147,492)^{* *}$ \\
\hline \multicolumn{3}{|l|}{2002} \\
\hline \multicolumn{3}{|l|}{ Health utilization } \\
\hline Outpatient visits & $48.45(26.28)$ & $31.01(19.79)^{* * *}$ \\
\hline Hospital admission & $0.96(1.80)$ & $0.53(1.24)^{* * *}$ \\
\hline \multicolumn{3}{|l|}{ Health expenditure } \\
\hline Outpatient expenditure & $68,221(92,547)$ & NT $\$ 40,878(68,016)^{* * *}$ \\
\hline Inpatient expenditure & $44,680(161,130)$ & NT \$30,353 $(109,259)$ \\
\hline Total expenditure & $112,901(196,238)$ & NT $\$ 71,231(135,512)^{* *}$ \\
\hline \multicolumn{3}{|l|}{2003} \\
\hline \multicolumn{3}{|l|}{ Health utilization } \\
\hline Outpatient visits & $47.61(26.77)$ & $30.75(21.18)^{* * *}$ \\
\hline Hospital admission & $0.93(1.46)$ & $0.49(1.16)^{* * *}$ \\
\hline \multicolumn{3}{|l|}{ Health expenditure } \\
\hline Outpatient expenditure & $65,450(82,658)$ & NT $\$ 43,660(74,673)^{* * *}$ \\
\hline Inpatient expenditure & $51,990(130,574)$ & NT $\$ 28,604(110,154)^{* *}$ \\
\hline Total expenditure & $116,440(158,256)$ & NT $\$ 72,264(142,698)^{* * *}$ \\
\hline \multicolumn{3}{|l|}{2004} \\
\hline \multicolumn{3}{|l|}{ Health utilization } \\
\hline Outpatient visits & $52.20(32.24)$ & $32.92(22.74)^{* * *}$ \\
\hline Hospital admission & $0.95(1.64)$ & $0.53(1.26)^{* * *}$ \\
\hline \multicolumn{3}{|l|}{ Health expenditure } \\
\hline Outpatient expenditure & $76,943(98,539)$ & NT $\$ 45,534(73,231)^{* * *}$ \\
\hline Inpatient expenditure & $56,134(159,023)$ & NT $\$ 35,421(142,258)^{*}$ \\
\hline Total expenditure & $133,077(193,103)$ & NT $\$ 80,955(167,092)^{* * *}$ \\
\hline
\end{tabular}

Exchange rate between US\$:NT $\$=1: 30 .{ }^{*} \mathrm{p}<0.05,{ }^{* *} \mathrm{p}<0.01,{ }^{* * *} \mathrm{p}<0.001$. SD: standard deviation 
sociated with increased direct medical expenditures. ${ }^{44}$ In addition to sex, ophthalmic complications were associated with increased health care utilization. This finding was consistent with those of previous studies reporting high health care uti- lization and expenditures of patients with diabetes comorbid with physical complications. ${ }^{19-22}$

In addition, residing in rural areas and ophthalmic complications were highly associated with hospitalization. This find-

Table 3. Outpatient visits and total medical expenditure for the diabetic patients with depression disorder using the GEE model ( $\mathrm{N}=144$ )

\begin{tabular}{|c|c|c|c|c|c|c|c|c|}
\hline \multirow{3}{*}{$\overline{\text { Constant }}$} & \multicolumn{4}{|c|}{ Outpatient visits } & \multicolumn{4}{|c|}{ Total medical expenditure } \\
\hline & \multirow{2}{*}{$\begin{array}{c}\text { Coefficient } \\
19.26\end{array}$} & \multicolumn{2}{|c|}{$95 \% \mathrm{CI}$} & \multirow{2}{*}{$\frac{\mathrm{p} \text {-value }}{0.037}$} & \multirow{2}{*}{$\begin{array}{c}\text { Coefficient } \\
10,769\end{array}$} & \multicolumn{2}{|c|}{$95 \% \mathrm{CI}$} & \multirow{2}{*}{$\frac{p \text {-value }}{0.725}$} \\
\hline & & 1.17 & 37.35 & & & $-49,145$ & 70,683 & \\
\hline \multicolumn{9}{|l|}{ Demographics } \\
\hline \multicolumn{9}{|l|}{ Gender } \\
\hline \multicolumn{9}{|l|}{ Female (ref.) } \\
\hline Male & -6.27 & -12.12 & -0.42 & 0.036 & 4,814 & $-14,319$ & 23,947 & 0.622 \\
\hline \multicolumn{9}{|l|}{ Age } \\
\hline \multicolumn{9}{|l|}{$<45$ (ref.) } \\
\hline $45-64$ & 7.24 & -3.38 & 17.87 & 0.181 & 18,514 & $-16,247$ & 53,276 & 0.297 \\
\hline$\geq 65$ & 5.14 & -5.91 & 16.19 & 0.362 & -620 & $-36,775$ & 35,536 & 0.973 \\
\hline \multicolumn{9}{|l|}{ Urbanization } \\
\hline \multicolumn{9}{|l|}{ Urban (ref.) } \\
\hline Suburban & 4.47 & -13.40 & 22.34 & 0.624 & 8,716 & $-49,755$ & 67,186 & 0.770 \\
\hline Rural & 2.03 & -4.29 & 8.34 & 0.529 & 182 & $-20,479$ & 20,844 & 0.986 \\
\hline \multicolumn{9}{|l|}{ Socioeconomic status } \\
\hline \multicolumn{9}{|l|}{ Income status* } \\
\hline \multicolumn{9}{|l|}{$\geq \mathrm{NT} \$ 40,000$ ( $\geq \mathrm{US} \$ 1,333$ ) (ref.) } \\
\hline NT\$20,000-39,999 (US\$666-1,332) & 8.48 & -10.70 & 27.66 & 0.386 & 2,581 & $-60,178$ & 65,339 & 0.936 \\
\hline$<\mathrm{NT} \$ 20,000(<\mathrm{US} \$ 666)$ & 9.17 & -7.08 & 25.41 & 0.269 & 18,836 & $-34,309$ & 71,981 & 0.487 \\
\hline Dependents & 10.02 & -6.76 & 26.79 & 0.242 & 27,511 & $-27,373$ & 82,396 & 0.326 \\
\hline \multicolumn{9}{|l|}{ Disease character } \\
\hline \multicolumn{9}{|l|}{ Complications } \\
\hline Neurological & 7.34 & 0.67 & 14.01 & 0.031 & 5,615 & $-16,210$ & 27,441 & 0.614 \\
\hline Peripheral vascular & -5.79 & -14.90 & 3.33 & 0.214 & 8,182 & $-21,645$ & 38,009 & 0.591 \\
\hline Cardiovascular & 5.31 & -1.28 & 11.91 & 0.114 & 4,855 & $-16,729$ & 26,439 & 0.659 \\
\hline Renal & 6.81 & -0.44 & 14.05 & 0.066 & 6,383 & $-17,324$ & 30,090 & 0.598 \\
\hline Endocrine/metabolic & -0.87 & -6.93 & 5.19 & 0.778 & 884 & $-18,951$ & 20,719 & 0.930 \\
\hline Ophthalmic & 6.04 & 0.04 & 12.03 & 0.049 & 18,692 & -933 & 38,316 & 0.062 \\
\hline Others & 2.50 & -4.22 & 9.21 & 0.467 & $-4,920$ & $-26,903$ & 17,064 & 0.661 \\
\hline \multicolumn{9}{|l|}{ Diabetes } \\
\hline Type 1 & 8.30 & -7.44 & 24.05 & 0.301 & 662 & $-50,848$ & 52,173 & 0.980 \\
\hline Type 2 & -0.11 & -8.47 & 8.25 & 0.980 & 14,285 & $-13,063$ & 41,632 & 0.306 \\
\hline \multicolumn{9}{|l|}{ Time factor } \\
\hline \multicolumn{9}{|l|}{2000 (ref.) } \\
\hline 2001 & -2.28 & -5.79 & 1.22 & 0.202 & $-13,368$ & $-32,013$ & 5,277 & 0.160 \\
\hline 2002 & -3.00 & -6.51 & 0.51 & 0.094 & 1,068 & $-17,578$ & 19,713 & 0.911 \\
\hline 2003 & -2.46 & -5.97 & 1.05 & 0.169 & 3,459 & $-15,186$ & 22,105 & 0.716 \\
\hline 2004 & 0.00 & -3.51 & 3.51 & 1.000 & 25,837 & 7,192 & 44,483 & 0.007 \\
\hline
\end{tabular}

Exchange rate between US\$:NT\$=1:30. *dependents: including family dependents, students and the unemployed. GEE: general estimation equations, CI: confidence interval 
Table 4. Hospitalization of the diabetic patients with depression disorder using logistic regression models $(\mathrm{N}=144)$

\begin{tabular}{|c|c|c|c|c|}
\hline \multirow{2}{*}{ Variables } & \multicolumn{4}{|c|}{ Multivariate } \\
\hline & OR & & & p-value \\
\hline \multicolumn{5}{|l|}{ Demographics } \\
\hline \multicolumn{5}{|l|}{ Gender } \\
\hline \multicolumn{5}{|l|}{ Female (ref.) } \\
\hline Male & 1.512 & 0.622 & 3.678 & 0.362 \\
\hline \multicolumn{5}{|l|}{ Age } \\
\hline \multicolumn{5}{|l|}{$<45$ (ref.) } \\
\hline $45-64$ & 0.378 & 0.074 & 1.934 & 0.243 \\
\hline$\geq 65$ & 0.669 & 0.120 & 3.727 & 0.647 \\
\hline \multicolumn{5}{|l|}{ Urbanization } \\
\hline \multicolumn{5}{|l|}{ Urban (ref.) } \\
\hline Suburban & 0.000 & 0.000 & 0.000 & 0.999 \\
\hline Rural & 2.859 & 1.051 & 7.777 & 0.040 \\
\hline \multicolumn{5}{|l|}{ Socioeconomic status } \\
\hline \multicolumn{5}{|l|}{ Income } \\
\hline \multicolumn{5}{|l|}{$\geq \mathrm{NT} \$ 40,000$ ( $\geq \mathrm{US} \$ 1,333)$ (ref.) } \\
\hline NT\$20,000-39,999 (US\$666-1,332) & 6.727 & 0.339 & 133.552 & 0.211 \\
\hline$<\mathrm{NT} \$ 20,000(<\mathrm{US} \$ 666)$ & 4.233 & 0.339 & 52.814 & 0.263 \\
\hline Dependents & 5.677 & 0.426 & 75.667 & 0.189 \\
\hline \multicolumn{5}{|l|}{ Disease character } \\
\hline \multicolumn{5}{|l|}{ Complications } \\
\hline Neurological & 1.244 & 0.446 & 3.467 & 0.676 \\
\hline Peripheral vascular & 0.574 & 0.151 & 2.182 & 0.415 \\
\hline Cardiovascular & 0.904 & 0.344 & 2.373 & 0.837 \\
\hline Renal & 1.749 & 0.567 & 5.394 & 0.331 \\
\hline Endocrine/metabolic & 0.820 & 0.337 & 2.000 & 0.663 \\
\hline Ophthalmic & 3.002 & 1.167 & 7.720 & 0.023 \\
\hline Others & 1.822 & 0.660 & 5.026 & 0.247 \\
\hline \multicolumn{5}{|l|}{ Diabetes } \\
\hline Type 1 & 0.000 & 0.000 & 0.000 & 0.999 \\
\hline Type 2 & 1.453 & 0.458 & 4.607 & 0.525 \\
\hline
\end{tabular}

Dependents: including family dependents, students and the unemployed. Exchange rate between US\$:NT\$=1:30. CI: confidence interval, OR: odds ratio

ing was consistent with that of a previous study stating that depressed rural patients had high odds of being hospitalized for physical and mental illnesses. ${ }^{45}$ Ophthalmic complications are also associated with more health care utilization; this finding was consistent with that of previous studies reporting high health care utilization and expenditures of patients with diabetes comorbid with physical complications. ${ }^{19-22}$

Investigating health care utilization and expenditure for patients with diabetes comorbid with depression by using an insurance database has many advantages, including a large sample size, less resources required for psychiatric assessments, and the availability of longitudinal data for detecting incidence and risk factors. ${ }^{46}$

However, this study has several limitations. First, the primary data source in this study was from health insurance claim data. There may exist dual diagnoses, over- and underdiagnoses for billing purposes. ${ }^{34}$ In addition, some demographic variables, including education, occupation, marital status, lifestyle, physical activity, blood sugar control, and body weight, were also unavailable in the claims database. Third, this study was only adjusted for specific individual complications and not for the overall medical complexity (e.g., Diabetes complication severity index and Charlson comorbidity index) or psychiatric complexity (e.g., diagnosis of anxiety disorders), which are 
potential confounders. Forth, our study primarily focused on the comparison of health utilization and expenditures between patients with and without general depression disorder. However, future study may further examine the potential difference of health utilization and expenditure between patients with diabetes comorbid with major depression and minor depression. Finally, due to the limitation of data sources, this study can only examine research questions using data from 2000 to 2004. Future study may further examine whether health utilization and expenditures change after a decade among those patients with DM comorbid with and without depression disorders.

Different study designs and instruments may be considered when reviewing health care utilization and expenditures in future studies. ICD-9-CM 296.2x, 296.3x, 296.82, 300.4, $309.0,309.1$, and 311 were included in the definition of depression, ${ }^{23}$ forming a heterogeneous patient group. Therefore, disorders, commonly comorbid with diabetes, such as MDD, may be compared with the general population in future studies. Furthermore, patients with type 1 and type 2 diabetes should be examined. The effects of age, sex, outcomes, complications, and mortality on depression in patients with diabetes should be assessed. Last, continuous NHI follow-up studies are required as references for comparison with future epidemiological studies in this study population.

In conclusion, in this large-scale, population-based study, we revealed the health care utilization and expenditure of patients with diabetes comorbid with depression. Thus far, little research has been conducted for clinical practice with respect to health care utilization and expenditures of such patients in Asia, particularly in China. Our findings indicated that health care utilization and expenditures for patients with diabetes comorbid with depression are significantly higher than those for patients with diabetes without depression. Sex, complications, time, and urbanization are factors associated with health care utilization and expenditures. This study, conducted on patients from ethnic groups in Taiwan, provide valuable epidemiological information.

\section{Supplementary Materials}

The online-only Data Supplement is available with this article at https://doi.org/10.4306/pi.2017.14.6.770.

\section{Acknowledgments}

This study was supported by grants from the Kaohsiung Medical University Hospital (KMUH99-9M26) and Kaohsiung Municipal Ta-Tung Hospital (kmtth-100-010 and kmtth-101-013). This study is in part based on data from the National Health Insurance Research Database provided by the Bureau of National Health Insurance, Department of Health and managed by National Health Research Institutes (NHIRD-100-100 and NHIRD102-135). The interpretation and conclusions contained herein do not represent those of the aforementioned agencies.

\section{REFERENCES}

1. Akena D, Kadama P, Ashaba S, Akello C, Kwesiga B, Rejani L, et al. The association between depression, quality of life, and the health care expenditure of patients with diabetes mellitus in Uganda. J Affect Disord 2015;174:7-12.

2. Murray CJ, Vos T, Lozano R, Naghavi M, Flaxman AD, Michaud C, et al. Disability-adjusted life years (DALYs) for 291 diseases and injuries in 21 regions, 1990-2010: a systematic analysis for the Global Burden of Disease Study 2010. Lancet 2012;380:2197-2223.

3. Chien IC, Wu EL, Lin CH, Chou YJ, Chou P. Prevalence of diabetes in patients with major depressive disorder: a population-based study. Compr Psychiatry 2012;53:569-575.

4. Murray CJ, Lopez AD. Alternative projections of mortality and disability by cause 1990-2020: Global Burden of Disease Study. Lancet 1997;349: 1498-1504.

5. Kumar K, Gupta M. Clinical and socio-demographic determinants of psychological health and burden in family caregivers of patients with unipolar depression. Asian J Psychiatr 2014;9:51-56.

6. Lurie IZ, Manheim LM, Dunlop DD. Differences in medical care expenditures for adults with depression compared to adults with major chronic conditions. J Ment Health Policy Econ 2009;12:87-95.

7. Zimmet P, Alberti KG, Shaw J. Global and societal implications of the diabetes epidemic. Nature 2001;414:782-787.

8. Lin WH, Hsu CH, Chen HF, Liu CC, Li CY. Mortality of patients with type 2 diabetes in Taiwan: a 10-year nationwide follow-up study. Diabetes Res Clin Pract 2015;107:178-186.

9. Harris MI. Diabetes in America: epidemiology and scope of the problem. Diabetes Care 1998;21(Suppl 3):C11-C14.

10. Economic consequences of diabetes mellitus in the U.S. in 1997. American Diabetes Association. Diabetes Care 1998;21:296-309.

11. Amos AF, McCarty DJ, Zimmet P. The rising global burden of diabetes and its complications: estimates and projections to the year 2010. Diabet Med 1997;14(Suppl 5):S1-S85.

12. Wong KC, Wang Z. Prevalence of type 2 diabetes mellitus of Chinese populations in Mainland China, Hong Kong, and Taiwan. Diabetes Res Clin Pract 2006;73:126-134.

13. Banerjea R, Pogach LM, Smelson D, Sambamoorthi U. Mental illness and substance use disorders among women veterans with diabetes. Womens Health Issues 2009;19:446-456.

14. Werner RM, Greenfield S, Fung C, Turner BJ. Measuring quality of care in patients with multiple clinical conditions: summary of a conference conducted by the Society of General Internal Medicine. J Gen Intern Med 2007;22:1206-1211.

15. Banerjea R, Sambamoorthi U, Smelson D, Pogach LM. Chronic illness with complexities: mental illness and substance use among Veteran clinic users with diabetes. Am J Drug Alcohol Abuse 2007;33:807-821.

16. Piette JD, Kerr EA. The impact of comorbid chronic conditions on diabetes care. Diabetes Care 2006;29:725-731.

17. Ciechanowski PS, Katon WJ, Russo JE. Depression and diabetes: impact of depressive symptoms on adherence, function, and costs. Arch Intern Med 2000;160:3278-3285.

18. Katon WJ, Rutter C, Simon G, Lin EH, Ludman E, Ciechanowski P, et al. The association of comorbid depression with mortality in patients with type 2 diabetes. Diabetes Care 2005;28:2668-2672.

19. Clarke PM, Glasziou P, Patel A, Chalmers J, Woodward M, Harrap SB, et al. Event rates, hospital utilization, and costs associated with major complications of diabetes: a multicountry comparative analysis. PLoS Med 2010;7:e1000236.

20. Gulliford MC, Latinovic R, Charlton J. Diabetes diagnosis, resource utilization, and health outcomes. Am J Manag Care 2008;14:32-38.

21. Nichols GA, Brown JB. The impact of cardiovascular disease on medical care costs in subjects with and without type 2 diabetes. Diabetes Care 2002;25:482-486.

22. Williams R, Van Gaal L, Lucioni C; CODE-2 Advisory Board. Assessing 
the impact of complications on the costs of Type II diabetes. Diabetologia 2002;45:S13-S17.

23. Huang CJ, Lin CH, Lee MH, Chang KP, Chiu HC. Prevalence and incidence of diagnosed depression disorders in patients with diabetes: a national population-based cohort study. Gen Hosp Psychiatry 2012;34: 242-248.

24. Huang CJ, Chiu HC, Lee MH, Wang SY. Prevalence and incidence of anxiety disorders in diabetic patients: a national population-based cohort study. Gen Hosp Psychiatry 2011;33:8-15.

25. Huang CJ, Wang SY, Lee MH, Chiu HC. Prevalence and incidence of mental illness in diabetes: a national population-based cohort study. Diabetes Res Clin Pract 2011;93:106-114.

26. Anderson RJ, Freedland KE, Clouse RE, Lustman PJ. The prevalence of comorbid depression in adults with diabetes: a meta-analysis. Diabetes Care 2001;24:1069-1078.

27. Vamos EP, Mucsi I, Keszei A, Kopp MS, Novak M. Comorbid depression is associated with increased healthcare utilization and lost productivity in persons with diabetes: a large nationally representative Hungarian population survey. Psychosom Med 2009;71:501-507.

28. Nichols L, Barton PL, Glazner J, McCollum M. Diabetes, minor depression and health care utilization and expenditures: a retrospective database study. Cost Eff Resour Alloc 2007;5:4.

29. Simon GE, Katon WJ, Lin EH, Ludman E, VonKorff M, Ciechanowski $\mathrm{P}$, et al. Diabetes complications and depression as predictors of health service costs. Gen Hosp Psychiatry 2005;27:344-351.

30. Finkelstein EA, Bray JW, Chen H, Larson MJ, Miller K, Tompkins C, et al. Prevalence and costs of major depression among elderly claimants with diabetes. Diabetes Care 2003;26:415-420.

31. Egede LE, Zheng D, Simpson K. Comorbid depression is associated with increased health care use and expenditures in individuals with diabetes. Diabetes Care 2002;25:464-470.

32. Lloyd CE, Roy T, Nouwen A, Chauhan AM. Epidemiology of depression in diabetes: international and cross-cultural issues. J Affect Disord 2012; 142 Suppl:S22-S29.

33. Lin CC, Lai MS, Syu CY, Chang SC, Tseng FY. Accuracy of diabetes diagnosis in health insurance claims data in Taiwan. J Formos Med Assoc 2005; 104:157-163.

34. Liptzin B, Regier DA, Goldberg ID. Utilization of health and mental health services in a large insured population. Am J Psychiatry 1980;137:553558.
35. Huang CJ, Chiu HC, Hsieh HM, Yen JY, Lee MH, Chang KP, et al. Health care utilization and expenditures of persons with diabetes comorbid with anxiety disorder: a national population-based cohort study. Gen Hosp Psychiatry 2015;37:299-304.

36. Chien IC, Chang KC, Lin CH, Chou YJ, Chou P. Prevalence of diabetes in patients with bipolar disorder in Taiwan: a population-based national health insurance study. Gen Hosp Psychiatry 2010;32:577-582.

37. Gau SS, Chung CH, Gau CS. A pharmacoeconomic analysis of atypical antipsychotics and haloperidol in first-episode schizophrenic patients in Taiwan. J Clin Psychopharmacol 2008;28:271-278.

38. Hebert PL, Geiss LS, Tierney EF, Engelgau MM, Yawn BP, McBean AM. Identifying persons with diabetes using Medicare claims data. Am J Med Qual 1999;14:270-277.

39. Chiu HC, Shi HY, Mau LW, Wang GJ. The effects of a prospective case payment system on hospital charges for total hip arthroplasty in Taiwan. J Arthroplasty 2007;22:65-71.

40. Thomas J, Jones G, Scarinci I, Brantley P. A descriptive and comparative study of the prevalence of depressive and anxiety disorders in lowincome adults with type 2 diabetes and other chronic illnesses. Diabetes Care 2003;26:2311-2317.

41. Rabi DM, Edwards AL, Southern DA, Svenson LW, Sargious PM, Norton $\mathrm{P}$, et al. Association of socio-economic status with diabetes prevalence and utilization of diabetes care services. BMC Health Serv Res 2006;6:124.

42. Gu D, Reynolds K, Duan X, Xin X, Chen J, Wu X, et al. Prevalence of diabetes and impaired fasting glucose in the Chinese adult population: International Collaborative Study of Cardiovascular Disease in Asia (InterASIA). Diabetologia 2003;46:1190-1198.

43. Black G, Roberts RM, Li-Leng T. Depression in rural adolescents: relationships with gender and availability of mental health services. Rural Remote Health 2012;12:2092.

44. Wang W, Fu C, Zhuo H, Luo J, Xu B. Factors affecting costs and utilization of type 2 diabetes healthcare: a cross-sectional survey among 15 hospitals in urban China. BMC Health Serv Res 2010;10:244.

45. Rost K, Zhang M, Fortney J, Smith J, Smith GR Jr. Rural-urban differences in depression treatment and suicidality. Med Care 1998;36:10981107.

46. Chien IC, Chou YJ, Lin CH, Bih SH, Chou P, Chang HJ. Prevalence and incidence of schizophrenia among national health insurance enrollees in Taiwan, 1996-2001. Psychiatry Clin Neurosci 2004;58:611-618. 